Research Article

\section{Assessment of early initiation of breastfeeding and determinants among mothers of children under 24 months in Southeast Ethiopia: a community-based cross-sectional study}

\author{
Dube Gemeda Tuke ${ }^{1}$, Legesse Tadesse Wodajo ${ }^{2 *}$ and \\ Hiwot Zelalem ${ }^{3}$
}

${ }^{1}$ Mothers and Child Health Expert, Jeju Woreda Health Office, Arsi Zone, Arboye, Ethiopia ${ }^{2}$ Associate Professor, Department of Public Health, College of Health Science, Arsi University, Asela, Ethiopia

${ }^{3}$ Assistant Professor of Biostatics and Health Informatics, Department of Public Health, College of Health Science, Arsi University, Asela, Ethiopia

\section{Abstract}

Background: Early-initiation of breastfeeding is putting the newborns to the breast within the first hour of life. It is the first critical time they contact their mother outside of the womb. The current study aimed to assess the early initiation of breastfeeding in the study setting.

Objectives: To assess the level of early initiation of breastfeeding and its associated factors among mothers who had a baby of less than the age of 24 months in Jeju Woreda, Arsi Zone, Oromia, Ethiopia, 2019.

Methods: A community-based cross-sectional study conducted involving 487 mothers from September 18 to October 09, 2019. A multistage sampling technique was employed. First, the setting stratification done in urban and rural settings. Second, ten kebeles selected from both strata. The study participants identified by systematic random sampling technique using kebele log-books registration list as a scheme. The collected data were entered into Epi Info version 7.1.5.0 and exported to SPSS version 21.0.0.0 to analyze. Bivariate and multivariate logistic regression used to determine relations between independent factors and early initiation of breastfeeding. Nine variables became eligible for multivariate analysis at a $p$ - value less than 0.05 in bivariate. The final analyses done the significance of association decided using AOR with its $95 \% \mathrm{Cl}$, and $p$ - value at less than 0.05 .

Results: A $97 \%$ response rate achieved in this study. The prevalence of early breastfeeding initiation was $74.5 \%$. In multivariate analysis variables namely, mothers whose age category was 35 years and above $(A O R=2.34,95 \% \mathrm{Cl}:(1.07,5.11))$, Pre-lacteal feeding $(A O R=0.3795 \% \mathrm{Cl}(0.17,0.79))$, postpartum advice $(A O R=1.72,95 \% \mathrm{Cl}(1.01$, 2.95)) had a significant association.-

Conclusion and recommendations: The prevalence of early breastfeeding initiation was $(74.5 \%)$. The finding was low compared to the world health organization recommendation. A working towards discouraging pre-lacteal feeding and strengthening postnatal advice and focusing on ways to better reach young mothers were the recommendations to bring the prevalence in the study area to the recommended level.

\section{More Information}

${ }^{*}$ Address for Correspondence:

Legesse Tadesse Wodajo, Associate Professor Department of Public Health, College of Health

Science, Arsi University, Asela, Ethiopia,

Email: legesset2008@gmail.com

Submitted: October 19, 2021

Approved: October 28, 2021

Published: October 29, 2021

How to cite this article: Tuke DG, Wodajo LT, Zelalem $\mathrm{H}$. Assessment of early initiation of breastfeeding and determinants among mothers of children under 24 months in Southeast Ethiopia: a community-based cross-sectional study. Arch Food Nutr Sci. 2021; 5: 032-039.

DOI: 10.29328/journal.afns. 1001030

ORCiD: orcid.org/0000-0002-7853-2723

Copyright License: () 2021 Tuke DG, et al. This is an open access article distributed under the Creative Commons Attribution License, which permits unrestricted use, distribution, and reproduction in any medium, provided the original work is properly cited.

Keywords: Breastfeeding; Early initiation; Brest feeding initiation; Ethiopia

Abbreviation: ANC: Antenatal Care; AOR: Adjusted Odd Ratio; BSc: Bachelor of Science; CBF: Continued Breast Feeding; $\mathrm{Cl}$ : Confidence Interval; COR: Crude Odd Ratio; DHS: Demographic Health Survey; EIBF: Early Initiation of Breast Feeding; ETB: Ethiopian Birr; HC: Health Center; HEW: Health Extension Worker; HF: Health Facility; HP: Health Post; HSTP: Health Sector Transformation Plan; IMR: Infant Mortality Rate; LB: Live Birth; NMR: Neonatal Mortality Rate; PPS: Probability Proportion to Size; SPSS: Statistical Package for Social Science; SRS: Simple Random Sampling; SSA: Sub-Sahara Africa; U5Mr: Under-five Mortality; WHO: World Health Organization

Check for updates

OPEN ACCESS 


\section{Introduction}

Optimal breastfeeding practices, include initiation of breastfeeding, exclusive breastfeeding (EBF), and continued breastfeeding (CBF) for up to two years or beyond [1]. The early initiation of breastfeeding (EIBF) is putting the newborns to the breast within the first hour of life, which is the first critical time they contact their mother outside of the womb [2]. World Health Organization (WHO) recommended breastfeeding should have initiated within the first hour of life [3]. The first milk (Colostrum) contains a large number of protective factors /antibodies/ that carry from mothers to their children and help to combat preventable diseases [4].

Globally, two out of five newborns (42\%) are put to the breast within the first one hour of their life. This rate is significantly varying across the regions, from $32 \%$ in East Asia and the Pacific to 65\% in Eastern and Southern Africa [5]. A survey conducted on Demographic Health Survey (DHS) in the Sub-Saharan Africa (SSA) region show that EIBF within one hour of birth was $50.5 \%$ which was a little bit greater than those started within 1 to 24 hours of life and more than three times of newborn started to initiate after 1 day of life. Exclusive BF declines from $64 \%$ at the time of birth to $20 \%$ at the end of the fifth month of age and CBF at the one year was $89.5 \%$ whereas at two years was $53.7 \%$ [6]. Results of the study conducted in the kingdom of Saudi Arabia show that the prevalence of EIBF were $43.6 \%, 27 \%$, and $21 \%$ within one hour of life, 1-24 hours, and more than 24 hours of life respectively [7].

According to Ethiopia DHS of 2016, 73\% of the newborns were put to the breast within one hour whereas nearly all (92\%) of them were within one day of their life. However, there was a huge difference across the region that extended from $42 \%$ in Afar to $78.2 \%$ in the Somali region, which is a little bigger than $76.7 \%$ in the Oromia region [8].

Immediate skin-to-skin contact after birth and initiating breastfeeding within one hour of baby's life keep their body temperature warm, builds up their immune system, boost regular milk production, promotes mother-infant bonding, and even increases the chance of continuing exclusive breastfeeding $[5,8,9]$ and also have physiologic, social and psychological benefit for both mother and infant [10]. Delayed initiation of Breast-Feeding (BF) increases the risk of neonatal death. After one day late, resulting in a risk of neonatal death. Conversely, EIBF within one hour of birth can reduce up to $22.3 \%$ of all newborns mortality [11].

Previous researches that have been done in a different part of Ethiopia show that the prevalence of EIBF within one hour of a baby's life was ranging from $88.5 \%$ to $48.7 \%$ [12-17]. EIBF and EBF can meaningfully reduce child mortality. Studies that are conducted in different countries show putting newborns to the breast and initiate within one day of life reduce all neonatal deaths and other neonatal morbidities like hypothermia, sepsis, diarrhea, and pneumonia [17,18-21].
Ethiopian Health Sector Transformation Plan (HSTP), set 2020 targets to reduce Under Five Mortality (U5Mr), Infant Mortality Rate (IMR), and Neonatal Mortality Rate (NMR) from 68 to 30/1000 (Live Birth) LB, from 46 to 20/1000LB and 27 to $10 / 1000$ LB respectively [22]. To meet this predetermined target, the findings of studies on EIBF may contribute their best.

There is a regional variation of EIBF rate between countries (Ethiopia and Tanzania) and even different areas within Ethiopia [23,24]. This might base on different Socioculture and beliefs of the different areas that may contribute to this variation. Improving EIBF within the first hour of life contributes to the exclusiveness and duration of breastfeeding [25]. Therefore, Socio-Cultural and beliefs factors in this study area were to be assessed to develop a strategy to overcome them.

Data of EDHS from 2000, 2005, 2011, and 2016 shows that the proportion of $\mathrm{EIBF}$ is $47.4 \%, 66.2 \%, 51.5 \%$, and $73.3 \%$ respectively which is fluctuating over years, and indicates as there is a gap of performance and needs improvement for its consistency.

Despite all these, no similar study was conducted in the study area preceding this study as to the knowledge of the author. For this reason, this study was conducted. The Jeju woreda is in Arsi Zone, Oromia regional state, Ethiopia at 182 $\mathrm{km}$ from AA, the capital city of the country. According to the 2007 Ethiopian census projection, the estimate of the total population of is 152,847 of which 75,812 (49.6\%) are females [26].

\section{Materials and methods}

\section{Study design}

A quantitative community-based cross-sectional study was conducted from September 18, 2019, to October 09, 2019, to determine the proportion of early initiation of breastfeeding and associated factors in the study area.

\section{Population}

All mothers who have children less than 24 months of age and live in Jeju Woreda at least for the six months before the data collection period were considered as source population while the study population was mothers who have children less than 24 months of age and selected from the community by systematic random sampling. Mothers who are unable to respond due to illness or mental problems were considered as exclusion.

\section{Sample size and sampling procedure}

Sample size determination: The sample size was computed based on single population proportion formula assuming the prevalence (P) $67.3 \%$ that was taken from a previous study [27]. A $z$ - value of 1.96 with a $95 \%$ confidence level will be used and a 5\% margin of error. 
- Sample Size $(\mathrm{n})=\mathrm{Z}_{\alpha / 2}{ }^{2} \mathrm{P}(1-\mathrm{P}) / \mathrm{W}^{2}$

- $=1.96^{2} * 0.673(1-0.673) / 0.05^{2}=338$

The size of the study population in the study area is 3003 which is less than 10,000 . So, by using the correction formula sample size is minimized to the final one.

- Using correction formula, $n_{\mathrm{f}}=\mathrm{n}_{\mathrm{i}} /\left(1+\mathrm{n}_{\mathrm{i}} / \mathrm{N}\right)$

- $=338 /(1+338 / 3003)=304$

- $\quad$ Applying design effect $=304 * 1.5=456$

- Then $10 \%$ non-response consideration $=0.1 * 456=46$

- The final sample size was $=456+46=502$

Moreover, the sample size was calculated for the second objective (factors associated with EIBF) using Epi info software version 7 by a formula for estimating the difference between two population proportions as indicated in the Table 1. The assumption taken into consideration were $95 \%$ of Confidence level, $5 \%$ desired precision, the ratio of unexposed to exposed 1:1, and 10\% non-response rate.

Sampling procedure: First, a stratified random sampling technique was applied based on the urban and rural setup. Accordingly, the total kebeles are divided into two strata (i.e. urban and rural). Then ten kebeles (35\% of total kebeles) were selected through a simple random sampling technique by lottery method which proportionally allocate to the number of kebeles in each stratum. So, one kebele from three urban kebeles and nine kebeles from 26 rural kebeles were selected. Then, 564 total sample sizes distribute over the 10 kebeles proportionally to the number of their study population. Since there is a list of all mothers who have children less than 24 months of age exist in the health post for the administration purpose, these lists are used as the sample frame of the study. Then the number of study participants was taken from the list by systematic random sampling method. The total number of mothers with children less than 24 months of age in the selected 10 kebele's (1126) was divided into a final sample size (502) to obtain an interval after $(\mathrm{K}=2)$ which another sample was taken next to the prior one. The first mothers interviewed were selected by lottery method and the second mother was selected from first and second. When two infants less than 24 months of age (including twins) were presented in one household one child was selected in the lottery method for participation (Figure 1).

\section{Variables of study}

Dependent variable: Early initiation of breastfeeding.

Independent variables: Independent variables are grouped into three as follows.

Demographic and Socio-economic factors: Education status, monthly family income, place of residence, occupation, marital status, age of mother and infant, sex of the infant.

Cultural and beliefs related factors: Perception of Prelacteal feeding, Perception of colostrum discarding.

Health service-related factors: Antenatal care follow up, ANC follow up with partner, delivery assisted by the health professional who carried out ANC, place of delivery.

\section{Operational definition}

Early initiation of breast feeding: The proportion of children born in the last 24 months who were put to the breast within one hour of birth [28].

Exclusive breast feeding: The proportion of infants aged 0-5 months who are feed exclusively with breast milk.

Delayed initiation of breastfeeding: The proportion of children born in the last 24 months who were not put to the breast within one hour of birth or put to the breast after one birth.

Residence: The state of living in a study area at least for the past six months from the data collection time.

\section{Data collection procedure (instruments, personnel and measurement)}

A structured interviewer questionnaire was prepared after reviewing a previous study on a similar topic, EDHS report, and WHO indicators to measure EIBF. Initially, the questionnaire was prepared in English version then translated to Afan Oromo which is the local language, and back to the English version again for its consistency. The questionnaire that is prepared in Afan Oromo was used for data collection. This tool was pass through pretest in neighboring kebele for its appropriateness of information collection and corrective action was taken as necessary for the final use. The questionnaire has three parts. Part one addresses demographic and socio-economic variables like occupation, place of residence, education status, and family income. Part two comprises variables related to culture and beliefs (i.e. perception of colostrum discarding

Table 1: Sample size calculation for the second objective of the study on early initiation of breastfeeding and associated factors among mothers of children under 24 months of age in Jeju district, Arsi zone, Ethiopia, 2019.

\begin{tabular}{|c|c|c|c|c|c|}
\hline \multirow{2}{*}{ SN } & \multirow{2}{*}{ Predictors of EIBF } & \multicolumn{2}{|c|}{ EIBF } & \multirow{2}{*}{ Sample size } & \multirow{2}{*}{ Reference } \\
\hline & & Exposed & Unexposed & & \\
\hline 1 & Formal education of the mother & Yes $(74.3 \%)$ & No $(52.5 \%)$ & 170 & 33 \\
\hline 2 & Mother hospital admission & Yes $(28.6 \%)$ & No $(70.4 \%)$ & 104 & 33 \\
\hline 3 & Place of delivery & Health institution (32.2\%) & Home $(91.4 \%)$ & 26 & 33 \\
\hline 4 & Advised on timely initiation of breastfeeding after delivery & Yes $(89.1 \%)$ & No $(35.5 \%)$ & 32 & 33 \\
\hline
\end{tabular}

* Since, the sample size is largest for the first objective, it was considered as the final sample size. 


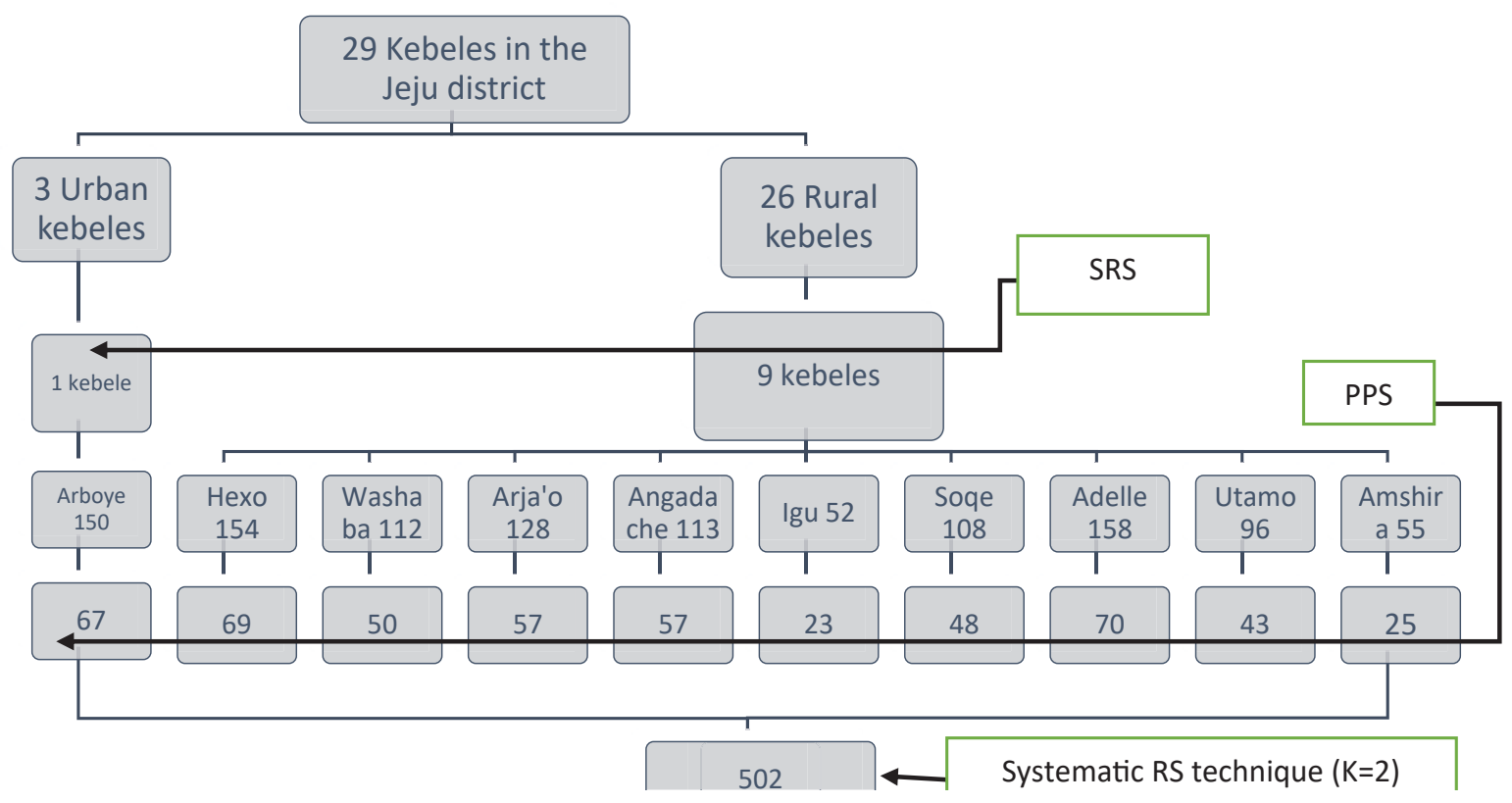

Figure 1: Schematic presentation of the sampling procedure for studying on initiation of breastfeeding.

and perception of pre-lacteal feeding) whereas variables concerning health-related service delivery ANC, PNC, and mode of delivery were addressed in part three.

Six grade 10 completed students have participated as data collectors. They can collect real information and reduce/avoid bias related to data collection. Two BSc midwives were also assigned, supervisors. All data collectors and supervisors were trained on issues like the purpose of the study, how to collect data, and the ethics of data collection for one day, before data collection.

During data collection completeness and appropriateness of questionnaire, the filling was checked by the supervisor and principal investigator daily, and feedback to data collectors was given immediately.

\section{Data quality assurance}

To avoid bias as much as possible data quality was controlled by different activities. Translation of English version questionnaire to local language (i.e. Afan Oromo) version for ensuring its consistency. One-day training for data collectors on the purpose of the study and on how to collect quality data was given. To avoid any data contamination questionnaire was pre-tested in other kebele on $5 \%$ of the sample size. Data collectors and supervisors were also not from the health sector, as bias may be made to increase their contribution to EIBF. Closer follow-up and supervision during data collection were also some methods of data quality assurance. For all questionnaires code was given to avoid redundancies or missing of questionnaire during data entered into Epi-info. Another activity was done for quality assurance included continuous communication during data collection between data collectors, supervisor, and investigator were conducted.

\section{Data processing and analysis}

Collected data were entered into Epi Info version 7.1.5.0 computer software based on the order of their code sequence. Then this data was exported to SPSS version 21.0.0.0 and cleared. Then value was given and a descriptive data characteristics report was done. Bivariate analysis was computed to examine the relationships between outcomes and predictors variables. Nine independent variables had a $p$ - value less than or equal to 0.05 in bivariate analysis. We selected them for the multivariate logistic regression analysis. During the multivariate logistic regression analysis, the Crude Odds Ratio (COR) and Adjusted Odds Ratio (AOR) were computed to determine the association between independent factors and response variables. The level of association was checked using AOR, its $95 \% \mathrm{CI}$, and $p$ - value. A $p$ - value less than 0.05 was used to decide a statistically significant association.

Ethical issue: Ethical clearance was obtained from the Ethical Review Board of the College of Health Sciences of Arsi University. Written informed consent was obtained from each participating mother [relative in case the age is less than 18 years] after explaining to them all the purpose of the study. The right of the participants to withdraw from the interview at any step was assured. Any personal identifiers have been differed during the study and replaced by identification numbers (codes).

\section{Results}

\section{Socio-demographic characteristics}

A total number of 487 mothers of children less than or equal to 24 months were included in the study with a $97 \%$ response rate. The mean (+ SD) of the participants was 28.76 ( \pm 5 ) years. Concerning children's sex more than 255 (52.4\%) 
were male and $232(47.6 \%)$ were female. The mean $(+\mathrm{SD})$ age of the children was $12.51( \pm 6.12)$ (Table 2 ).

\section{Reasons of failure to initiate breastfeeding within one hour of birth}

All the participants were breastfed in the past and the result about early initiation of breastfeeding of respondents showed that the majority of the 487 (74.5\%) within one hour of birth whereas 124 (25.5\%) were initiated after one hour of birth (Figure 2).

\section{Results of pre-lacteal feeding and colostrum feeding practices}

Among a total of 487 respondents, $450(92.4 \%)$ were

Table 2: Socio-demographic characteristics of study participants at Jeju district, Arsi zone, Ethiopia, $2019(n=487)$

\begin{tabular}{|c|c|c|c|}
\hline Variables & Variable Category & Number & Percent (\%) \\
\hline \multirow{2}{*}{ Residence } & Town & 67 & 13.8 \\
\hline & Rural & 420 & 86.2 \\
\hline \multirow{5}{*}{$\begin{array}{l}\text { Mothers age group } \\
\text { category and mean }( \pm S D)\end{array}$} & $18-24$ years & 88 & 18.1 \\
\hline & $25-29$ years & 203 & 41.7 \\
\hline & $30-34$ years & 124 & 25.5 \\
\hline & $45-35$ years & 72 & 14.8 \\
\hline & Mean $( \pm S D)$ & 487 & $28.76( \pm 5)$ \\
\hline \multirow{2}{*}{ Marital status } & Married & 459 & 94.3 \\
\hline & Others* & 28 & 5.7 \\
\hline \multirow{2}{*}{ Religious } & Muslim & 344 & 70.6 \\
\hline & Others ${ }^{* *}$ & 143 & 29.4 \\
\hline \multirow{2}{*}{ Ethnic } & Oromo & 429 & 88.1 \\
\hline & Amhara & 58 & 11.9 \\
\hline \multirow{3}{*}{ Mothers education status } & Uneducated & 253 & 52.0 \\
\hline & Primary & 199 & 40.9 \\
\hline & Secondary and more & 35 & 7.2 \\
\hline \multirow{5}{*}{ Occupation of mothers } & House-wife & 406 & 83.4 \\
\hline & Farmer & 31 & 6.4 \\
\hline & Merchant & 23 & 4.7 \\
\hline & Daily Laborer & 12 & 2.5 \\
\hline & Others ${ }^{* * *}$ & 15 & 3.1 \\
\hline \multirow{3}{*}{$\begin{array}{l}\text { Average monthly family } \\
\text { income }\end{array}$} & $<=1500$ & 241 & 49.5 \\
\hline & $1501-3000$ & 149 & 30.6 \\
\hline & $>=3001$ & 97 & 19.9 \\
\hline \multirow{2}{*}{ Sex of the child } & Male & 255 & 52.4 \\
\hline & Female & 232 & 47.6 \\
\hline \multirow{4}{*}{$\begin{array}{c}\text { Children's age group } \\
\text { category }\end{array}$} & $<=6$ months & 91 & 18.7 \\
\hline & $7-12$ months & 151 & 31 \\
\hline & $>=12$ months & 245 & 50.3 \\
\hline & mean $( \pm S D)$ & 487 & $12.51( \pm 6.12)$ \\
\hline
\end{tabular}

*-Single, Divorced and widowed, **-Orthodox and protestant, ${ }^{* * *}$-Governmental employee Maidservant, student, ${ }^{* * * *}$ Reported estimation after converting income in kind to cash depending on the local market cost; [cattle, cereals, vegetables, fruits, and others].

Reasons of failure to initiate breastfed within one hour of birth (\%)

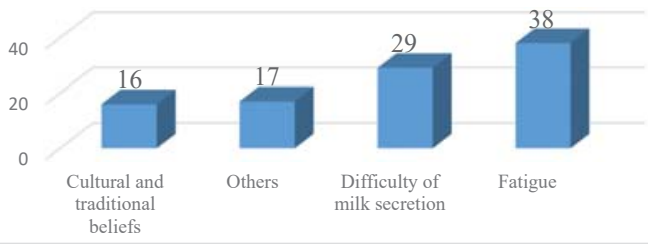

Figure 2: Percentage of reasons of failure to initiate breastfeeding within one hour of birth in study participants at Jeju district, Arsi zone, Ethiopia, 2019. feed colostrum their child while $37(7.6 \%)$ were not. Concerning pre-lacteal feeding, more than 446 (91.6\%) of the respondents were not given any drinkable or eatable to the infants. Correspondingly, 41 (8.5\%) mothers were practiced pre-lacteal feeding and more than $32 \%$ of them gave water alone to the child (Figure 3).

\section{Results concerning health service characteristics of study participants}

Of the total study participants, 443 (91\%) of them had at least one antenatal care (ANC) visit and of them, 205 (45.7\%) had visited with their partner. Among mothers who had visit health facilities for ANC 369 (75.8\%) were advised on timely initiation of breastfeeding during that visit (Table 3).
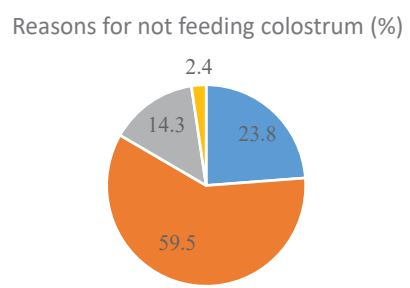

- Colostrum is dirty Difficulty of swallow

- Colostrum causes abdominal cramp in Others

Figure 3: Reasons for not fed colostrum in study participants at Jeju district, Arsi zone, Ethiopia, 2019.

Table 3: Health-related factors of the study participants of the early initiation of breastfeeding and associated factors among mothers of children under 24 months of age in Jeju Woreda, Arsi zone, Ethiopia, $2019(n=487)$.

\begin{tabular}{|c|c|c|c|}
\hline Variables & Category & $\boldsymbol{n}$ & $\%$ \\
\hline \multirow{2}{*}{ Ever breastfeeding } & Yes & 487 & 100.0 \\
\hline & No & 0 & 0.0 \\
\hline \multirow{2}{*}{ Early initiation of breastfeeding } & Within one hour & 363 & 74.5 \\
\hline & After one hour & 124 & 25.5 \\
\hline \multirow{2}{*}{ Colostrum } & Give to child & 450 & 92.4 \\
\hline & Discarded & 37 & 7.6 \\
\hline \multirow{2}{*}{ Pre-lacteal feeding } & Yes & 41 & 8.4 \\
\hline & No & 446 & 91.6 \\
\hline \multirow{2}{*}{ ANC follow up } & Yes & 443 & 91.0 \\
\hline & No & 44 & 9.0 \\
\hline \multirow{3}{*}{ Number of ANC visits (443) } & Once & 53 & 10.9 \\
\hline & Two to three & 261 & 53.6 \\
\hline & Four and more & 129 & 26.5 \\
\hline \multirow{2}{*}{ Advised on EIBF during ANC visit (443) } & Yes & 369 & 75.8 \\
\hline & No & 74 & 15.2 \\
\hline \multirow{2}{*}{ ANC visit with Husband (443) } & Yes & 204 & 41.9 \\
\hline & No & 239 & 49.1 \\
\hline \multirow{2}{*}{$\begin{array}{l}\text { Advised on EIBF during ANC visit with } \\
\text { husband (204) }\end{array}$} & Yes & 132 & 27.1 \\
\hline & No & 72 & 14.8 \\
\hline \multirow{2}{*}{ Place of delivery } & Health Institution & 358 & 73.5 \\
\hline & Others ${ }^{*}$ & 129 & 26.5 \\
\hline \multirow{2}{*}{ Mode of delivery } & Through vagina & 465 & 95.5 \\
\hline & Cesarean section & 22 & 4.5 \\
\hline \multirow{2}{*}{$\begin{array}{l}\text { The health facility visited for ANC and give } \\
\text { birth was the same (358) }\end{array}$} & Yes & 277 & 56.9 \\
\hline & No & 81 & 16.6 \\
\hline \multirow{2}{*}{$\begin{array}{l}\text { Health professional assisted ANC and } \\
\text { Delivery was the same (358) }\end{array}$} & Yes & 176 & 36.1 \\
\hline & No & 182 & 37.4 \\
\hline \multirow{2}{*}{ Immediately advised on EIBF after delivery } & Yes & 266 & 54.6 \\
\hline & No & 221 & 45.4 \\
\hline
\end{tabular}

*Home, on the way to the health facility or in the ambulance. 
Table 4: Multivariate logistic regression analysis showed factors associated with early initiation of breastfeeding among mothers of children less than 24 months in Jeju Woreda, Arsi zone, Oromia, Ethiopia, 2019.

\begin{tabular}{|c|c|c|c|c|c|c|}
\hline \multirow{2}{*}{\multicolumn{2}{|c|}{ Variables }} & \multicolumn{2}{|c|}{ EIBF } & \multirow{2}{*}{ COR $(95 \% \mathrm{CI})$} & \multirow{2}{*}{ AOR $(95 \% \mathrm{Cl})$} & \multirow{2}{*}{$p$ - value } \\
\hline & & Within one hour & After one hour & & & \\
\hline \multirow{4}{*}{ Mothers age group category } & 18 - 24 years & $71(14.6)$ & $17(3.5)$ & 1 & 1 & \\
\hline & $25-29$ years & $162(33.3)$ & $41(8.4)$ & $1.06(0.56,1.99)$ & $1.12(0.57,2.21)$ & 0.74 \\
\hline & $30-34$ years & $89(18.3)$ & $35(7.2)$ & $1.64(.851,3.171)$ & $1.59(.777,3.269)$ & 0.20 \\
\hline & $35-45$ years & $41(8.4)$ & $31(6.4)$ & $3.16(1.56,6.39)^{\star}$ & $2.34(1.07,5.11)^{\star *}$ & 0.03 \\
\hline \multirow{2}{*}{ Marital status of mothers } & Married & $348(71.5)$ & $111(22.8)$ & 1 & 1 & \\
\hline & Others $^{\infty}$ & $15(3.1)$ & $13(2.7)$ & $0.57(0.38,0.87)^{*}$ & $1.07(0.42,2.70)$ & 0.89 \\
\hline \multirow{3}{*}{ Mothers education status } & Uneducated & $176(36.1)$ & $77(15.8)$ & 1 & 1 & \\
\hline & Primary & $160(32.9)$ & $77(15.8)$ & $0.56(.36, .87)^{*}$ & $0.69(0.42,1.11)$ & 0.13 \\
\hline & Secondary and more & $27(5.6)$ & $8(1.6)$ & $0.68(0.29,1.56)$ & $1.59(0.62,4.07)$ & 0.33 \\
\hline \multirow{3}{*}{ Average monthly family income } & $<=1500$ & $174(35.7)$ & $67(13.8)$ & 1 & 1 & \\
\hline & $1501-3000$ & $108(22.2)$ & $41(8.4)$ & $0.99(0.62,1.56)$ & $1.21(.72,2.05)$ & 0.47 \\
\hline & $>=3001$ & $81(16.6)$ & $16(3.3)$ & $0.51(0.28,0.94)^{*}$ & $0.64(0.32,1.26)$ & 0.20 \\
\hline \multirow{2}{*}{ Colostrum } & Give to child & $346(71.0)$ & $104(21.4)$ & 1 & 1 & \\
\hline & Discarded & $17(3.5)$ & $20(4.10$ & $3.91(1.98,7.75)^{*}$ & $1.79(0.80,4.02)$ & 0.16 \\
\hline \multirow{2}{*}{ Pre-lacteal feeding } & Yes & $18(3.7)$ & $23(4.7)$ & 1 & 1 & \\
\hline & No & 345 & 101 & $0.23(0.12,0.44)^{*}$ & $0.37(0.17,0.79)^{* *}$ & 0.01 \\
\hline \multirow{2}{*}{ ANC follow up } & Yes & $342(70.2)$ & $101(20.7)$ & 1 & 1 & \\
\hline & No & $21(4.3)$ & $23(4.7)$ & $0.27(0.14,0.507)^{*}$ & $1.74(0.80,3.76)$ & 0.16 \\
\hline \multirow{2}{*}{ Place of delivery } & Health Facility & $286(58.7)$ & $72(14.8)$ & 1 & 1 & \\
\hline & Others ${ }^{\imath}$ & $77(15.8)$ & $52(10.7)$ & $2.68(1.73,4.15)^{*}$ & $1.27(.71,2.28)$ & 0.42 \\
\hline \multirow{2}{*}{$\begin{array}{l}\text { Immediately advice on EIBF after } \\
\text { delivery }\end{array}$} & Yes & $221(45.4)$ & $45(9.2)$ & 1 & 1 & \\
\hline & No & $142(29.2)$ & $79(16.2)$ & $2.73(1.79,4.17)^{*}$ & $1.72(1.01,2.95)^{\star *}$ & 0.04 \\
\hline
\end{tabular}

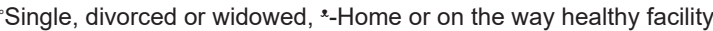

\section{Multivariate analysis and factors associated with early initiation of breastfeeding among mothers}

During multiple variable logistic regression analysis, three variables including the age of the mothers, pre-lacteal feeding, and information about early initiation of breastfeeding delivered immediately after delivery were showed significantly associated with early initiation of breastfeeding (Table 4).

\section{Discussion}

The overall proportion of early initiation of breastfeeding among mothers was $74.5 \%$. According to WHO classification of the rate of early initiation breastfeeding this finding was classified as a good rate since it was found between $50 \%$ and $89 \%$ range [31]. It was also comparable with national data $(73.3 \%)$ of the breast early initiation infants [8] and study conducted using demographic and health survey data in Ethiopia 74.3\% [30]. The finding was consistent with other studies conducted in Dembecha woreda, Northwest Ethiopia (73.1\%) [17], in Debre Tabor, northwest Ethiopia (76.8\%) [12], and in Motta district, East Gojjam, Amhara Region (78.8\%) [31]. However, the current study prevalence was smaller than the result of cross-sectional studies that have been conducted in the rural part of West Ethiopia (83.1\%) [15], Dale woreda, south Ethiopia (83.7\%) [32]. Furthermore, it was much smaller than the finding of previous studies that have been conducted in Nekemte town (88.5\%) [14] and Kassala, eastern Sudan (87.2\%) [33]. Discrepancies might be from socio-demographic difference, sample size, and sampling procedure of study participants between current and previous studies. However, it was relatively higher as compared to the finding of the study in Tiyo woreda (67.3\%) [27], and much greater than another study that was done in the Gurage zone (47.3\%) [34]. But, the prevalence of the current study is much higher than previous studies conducted in south Gonder (48.7\%) [16], and South Sudan (52\%) [35]. These higher variations might be due to variation in socio-demographic characteristics, sample size, and health promotion practice differences.

Furthermore, the percentage of current study participants who put their children to the breast within one hour of delivery was greater than a similar study conducted in Tanzania (51\%) [23], and in Bangladesh (67\%) [36]. Differences might arise from socio-demographic differences of the study settings and/or methods of investigations.

The current study indicates that from the total of 487 participants 450 (92.4\%) of them were fed their infants the colostrum. Whereas the remaining participants were squeezed out and discarded. This result was consistent with a finding of a study done in the rural part of Ethiopia (91.2\%) [15]. But it was greater than that of Dembecha (76.2\%) [17], Motta woreda (79.8\%) [31], and Debre Tabor (74.4\%) [12].

From the current study mothers' age group category was found significantly associated with the initiation of breastfeeding within the first hour of birth in multivariate logistic regression.

Mothers whose age group category was between 35 and 45 years were more than 2 times more likely to initiate breastfeeding after one hour of delivery when compared to those whose age was less than or equal to 24 years of age group category (AOR $=2.34,95 \% \mathrm{CI},(1.07-5.11)$ ), $p=0.03$. 
Another predictor factor of EIBF was pre-lacteal feeding. This finding was in agreement with the findings of studies conducted in Raya Kobo [37], rural parts of Ethiopia [15], Dembecha woreda [17], Debre Berhan [38], Motta woreda [31], and the kingdom of Saudi Arabia [7].

This study indicates that mothers who were not given any eatable or drinkable to their infant were $63 \%$ less likely to start breastfed initiation after one hour of delivery (AOR = $0.37,95 \% \mathrm{CI},(0.17-0.79)), p=0.01$, than those who were not given any pre-lacteal feeding. The predominant any eatable or drinkable gave to the infants before initiating breastfed was water alone $48.8 \%$ [20], followed by water with sugar $25.6 \%$ [11].

Another independent factor that had an association with breast initiation within an hour of birth, was postnatal advice or information given to mothers. The present study indicates that mothers who didn't receive information about breastfed initiation were nearly 2 times more likely to start the initiation of breastfeeding lately (AOR $=1.72,95 \% \mathrm{CI},(1.01,2.94)$ ), $p=0.04$. Furthermore, advice on initiation of breastfeeding delivered immediately after birth showed that a significant association with breastfed initiation and it was in line with studies conducted in rural parts of Ethiopia and Goba. Of the total participants, $358(73.5 \%)$ mothers were delivered in health facilities. However, only 248 (69.3\%) of them received information immediately after giving birth on breastfeeding initiation within one hour of birth as recommended by the world health organization. This result suggests that missed opportunities as advice immediate after delivery were significantly associated with early breastfeeding initiation.

In contrast, to previous studies conducted in the Gurage zone, Motta town, Tiyo woreda, Bahir Dar city, South Gonder, Goba woreda, Systematic review in Ethiopia, in the kingdom of Suad Arabi, Bangladesh, Tanzania, and in Nepal current study was not found significance prediction of a place of delivery, mode of delivery and residence to EIBF $[7,13,16,23,24,31,34$, $36,39,40]$.

The strength of this study was that it was a communitybased approach data of this study was entered by Epi Info and analyzed by SPSS computer software. The cross-sectional nature of this study limits determination of the cause-effect relationship from the association between early initiation of breastfeeding and its predictor factors. Recall bias might occur because study participants included mothers of children up to 2 years of age.

\section{Conclusion}

In general, the study revealed the proportion of initiating breastfeeding within one hour of birth among children less than or equal to 24 months of age was $74.5 \%$ and it was good practice according to WHO rate of initiation of breastfeeding classification. But it should be at least greater than $90 \%$. The study found some mothers discarded colostrum $(8 \%)$ and those who practice pre-lacteal feeding (9\%) both could negatively influence the timely initiation of breastfeeding. The older age group mothers (35-45 years) and mothers who give to newborn babies some form of pre-lacteal feeding tended to start breastfeeding later than recommended while those who get advice immediately after delivery on breastfed initiation were found significantly associated with early initiation of breastfeeding.

\section{Recommendations}

Based on the result of the current study some recommendations are suggested. Information on initiating breastfeeding should be provided to mothers emphasizing immediately after delivery (during post-natal care) by health service providers to increase their knowledge and awareness. It is also better to conduct community conversations to reduce/avoid bad traditional cultural practices and beliefs concerning pre-lacteal feeding practices. EIBF should also be promoted in all reproductive age group women and the community to avoid practices like pre-lacteal activities.

\section{Declarations}

Availability of data and materials: The datasets used and/or analyzed during the current study are available from the corresponding author.

Competing interests: Authors declare to have no conflict of interest.

\section{Contribution of the authors}

TGD developed the conception, design, data acquisition, analysis, and result writing. LT and HZ supported the study conception, designing, and data management and critically reviewed the report, and prepared the manuscript to the current level. Finally, all the authors read and approved the manuscript for publication.

\section{Acknowledgment}

The authors' thank also goes to Jeju woreda health office for they share the woreda's profile and all relevant information.

\section{References}

1. WHO. Global Nutrition targets 2025: breastfeeding policy brief (WHO/ NMH/NHD/14.7). Geneva 2014.

2. UNCEIF. From the first hour of life: Making the case for improved infant and young child feeding everywhere. New York: UNICEF; 2016.

3. WHO. Guideline: counseling of women to improve breastfeeding practices. Geneva: World Health Organization; 2018.

4. WHO. Early Initiation of Breastfeeding: the Key to Survival and Beyond. Geneva: World Health Organization; 2010.

5. UNICEF Wa. Capture the Moment: Early initiation of breastfeeding The best start for every newborn. New York: UNICEF; 2018.

6. Gebremedhin S. Core and optional infant and young child feeding indicators in Sub-Saharan Africa: a cross-sectional study. BMJ Open. 2019; 9: e023238.

PubMed: https://pubmed.ncbi.nlm.nih.gov/30782876/ 
7. Ahmed AE, Salih OA. Determinants of the early initiation of breastfeeding in the Kingdom of Saudi Arabia. Int Breastfeed J. 2019; 14: 13. PubMed: https://pubmed.ncbi.nlm.nih.gov/30984282/

8. Ethiopia Central Statistical Agency. Ethiopia Demographic and Health Survey 2016. Addis Ababa, Ethiopia, and Rockville, Maryland, USA CSA and ICF. 2016.

9. WHO. Guideline: protecting, promoting, and supporting breastfeeding in facilities providing maternity and newborn services. Geneva: World Health Organization. 2017

10. Brimdyr K, Cadwell K, Stevens J, Takahashi Y. An implementation algorithm to improve skin-to-skin practice in the first hour after birth. Matern Child Nutr. 2018; 14: e12571.

PubMed: https://pubmed.ncbi.nlm.nih.gov/29230957/

11. Edmond KM, Zandoh C, Quigley MA, Amenga-Etego, S, OwusuAgyei, S, Kirkwood, B.R. Delayed breastfeeding initiation increases risk of neonatal mortality. Pediatrics. 2006; 117: e380-386.

PubMed: https://pubmed.ncbi.nlm.nih.gov/16510618/

12. Abie BM, Goshu YA. Early initiation of breastfeeding and colostrum feeding among mothers of children aged less than 24 months in Debre Tabor, Northwest Ethiopia: a cross-sectional study. BMC Res Notes. 2019; 12: 65

PubMed: https://pubmed.ncbi.nlm.nih.gov/30696481/

13. Belachew A. Timely initiation of breastfeeding and associated factors among mothers of infants-age 0-6months old in Bahir Dar City, Northwest, Ethiopia, 2017: a community-based cross-sectional study. Int Breastfeed J. 2019; 14: 5

14. Wolde T, Birhanu B, Ejata E. Prevalence and Determinants of Timely Initiation of Breastfeeding among Lactating Mothers of Urban Dwellers in Western Ethiopia: A Community Based Cross-Sectional Study. Food Sci Quality Management. 2014; 31.

15. Hailemariam TW, Adeba W, Sufa A. Predictors of early breastfeeding initiation among mothers of children under 24 months of age in the rural part of West Ethiopia. BMC Public Health. 2014; 15

16. Mekonen L, Seifu W, Shiferaw Z. Timely initiation of breastfeeding and associated factors among mothers of infants under 12 months in South Gondar zone, Amhara regional state, Ethiopia; 2013. Int Breastfeed J. 2018; $13: 17$.

17. Ayalew $\mathrm{T}$, Tewabe $\mathrm{T}$, Ayalew $\mathrm{Y}$. Timely initiation of breastfeeding among first-time mothers in Bahir Dar city, North West, Ethiopia, 2016. Pediatr Res. 2019; 85: 612-616.

PubMed: https://pubmed.ncbi.nlm.nih.gov/30661083/

18. The Alive and Thrive Initiative. The Alive and Thrive Initiative on exclusive breastfeeding in rural Burkina Faso: a repeated crosssectional cluster, randomized trial Impact of early initiation of exclusive breastfeeding on newborn deaths. Alive Thrive. 2010. Fosu-Brefo R, Arthur E. Effect of timely initiation of breastfeeding on child health in Ghana. Health Econ Rev. 2015; 5: 8.

19. Mugadza G, Zvinavashe M, Gumbo FZ, Pedersen BS. Early breastfeeding initiation and incidence of neonatal sepsis in Chipinge District Zimbabwe. Int J Contemp Pediatr. 2018; 5: 1-5.

20. Mullany LC, Katz J, Li YM, Khatry SK, LeClerq SC, et al. BreastFeeding Patterns, Time to Initiation, and Mortality Risk among Newborns in Southern Nepal. J Nutrition. 2008; 138: 599-603. PubMed: https://www.ncbi.nlm.nih.gov/pmc/articles/PMC2366167/

21. Demissie BW, Abera BB, Chichiabellu TY, Astawesegn FH. Neonatal hypothermia and associated factors among neonates admitted to neonatal intensive care unit of public hospitals in Addis Ababa, Ethiopia. BMC Pediatr. 2018; 18: 263.

22. Ethiopia Ministry of Health. Health Sector Transformation Plan: 20082012EFY. Addis Ababa: Ethiopian Ministry of Health; 2015.

23. Exavery A, Kanté AM, Hingora A, Phillips JF. Determinants of early initiation of breastfeeding in rural Tanzania. Int Breastfeed J. 2015; 10: 27

PubMed: https://pubmed.ncbi.nlm.nih.gov/26413139/
24. Setegn T, Gerbaba M, Belachew T. Determinants of timely initiation of breastfeeding among mothers in Goba Woreda, South East Ethiopia: A cross-sectional study. BMC Public Health. 2011; 11: 217 PubMed: https://pubmed.ncbi.nlm.nih.gov/21473791/

25. Essential Nutrition Actions: Improving Maternal, Newborn, Infant and Young Child Health and Nutrition. Geneva: World Health Organization. 2013

26. Federal Democratic Republic of Ethiopia Population Census Commission. Summary and statistical report of the 2007 population and housing census: population size by age and sex. Addis Ababa: Federal Democratic Republic of Ethiopia, Population Census Commission. 2008.

27. Woldemichael BK, Kibie Y. Timely Initiation of Breastfeeding and Its Associated Factors among Mothers in Tiyo Woreda, Arsi Zone, Ethiopia: A Community- Based Cross-sectional study. Clin Mother Child Health. 2016; 13: 1-6.

28. UNICEF. Sustainable Development Goals global indicators are related to children. 2015. data.unicef.org/wp-content/uploads/2018/05/SDGBriefing-Notes-web-1.pdf

29. WHO. Infant and Young Child Feeding: A tool for assessing national practices, policies, and programs. Geneva, Switzerland: WHO; 2003.

30. John JR, Mistry SK, Kebede G, Manohar N, Arora A. Determinants of early initiation of breastfeeding in Ethiopia: a population-based study using the 2016 demographic and health survey data. BMC Pregnancy Childbirth. 2019; 19: 69.

31. Tewabe T. Timely initiation of breastfeeding and associated factors among mothers in Motta town, East Gojjam zone, Amhara regional state, Ethiopia, 2015: a cross-sectional study. BMC Pregnancy Childbirth. 2016; 16: 314

PubMed: https://pubmed.ncbi.nlm.nih.gov/27756253/

32. Beyene MG, Geda NR, Habtewold TD, Assen ZM. Early initiation of breastfeeding among mothers of children under the age of 24 months in Southern Ethiopia. Int Breastfeed J. 2017: 12 PubMed: https://pubmed.ncbi.nlm.nih.gov/28070207/

33. Hassan AA, Taha Z, Abdulla AM, Ali AA, Adam I. Assessment of initiation of breastfeeding practice in Kassala, Eastern Sudan: a community-based study. Int Breastfeed J. 2018; 13: 34 PubMed: https://pubmed.ncbi.nlm.nih.gov/30065774/

34. Shiferaw BZ, Mossa KA, Gashaw TB. Factors Associated with Early Initiation and Exclusive Breastfeeding Practices among Mothers of Infant's Age Less Than 6 Months. J Pediatr Neonatal Care. 2017: 7.

35. Tongun BJ, Sebit MB, Mukunya D, Ndeezi G, et al. Factors associated with delayed initiation of breastfeeding: a cross-sectional study in South Sudan. Int Breastfeed J. 2018; 13: 28

PubMed: https://pubmed.ncbi.nlm.nih.gov/30002722/

36. Karim F, Billah SM, Chowdhury MAK, Zaka N, Manu A, et al. Initiation of breastfeeding within one hour of birth and its determinants among normal vaginal deliveries at primary and secondary health facilities in Bangladesh: A case-observation study. PloS ONE. 2018; 13: e0202508. PubMed: https://pubmed.ncbi.nlm.nih.gov/30114288/

37. Legesse M, Demena M, Mesfin F, Haile D. Prelacteal feeding practices and associated factors among mothers of children aged less than 24 months in Raya Kobo district, North Eastern Ethiopia: a cross-sectional study. Int Breastfeed J. 2014; 9.

38. Argaw MD, Asfaw MM, Ayalew MB, Desta FB, Mavundla RT, et al. Factors associated with pre-lacteal feeding practices in Debre Berhan district, North Shoa, Central Ethiopia: a cross-sectional, communitybased study. BMC Nutrition. 2019; 5.

39. NDHS. Factors associated with early initiation of breastfeeding among Nepalese mothers: further analysis of Nepal Demographic and Health Survey, 2011.

40. Alebel A, Dejenu G, Mullu G, Abebe N, Gualu T, et al. Timely initiation of breastfeeding and its association with a birthplace in Ethiopia: a systematic review and meta-analysis. Int Breastfeed J. 2017; 12: 44 PubMed: https://www.ncbi.nlm.nih.gov/pmc/articles/PMC5627416/ 